University of Wollongong

Research Online

Faculty of Engineering and Information

Faculty of Engineering and Information

Sciences - Papers: Part A

Sciences

$1-1-2013$

\title{
Capacity deferral credit evaluation of renewable distributed generation
}

\author{
M A. Abdullah \\ University of Wollongong, maa267@uowmail.edu.au
}

K M. Muttaqi

University of Wollongong, kashem@uow.edu.au

\author{
A P. Agalgaonkar \\ University of Wollongong, ashish@uow.edu.au \\ D Sutanto \\ University of Wollongong, soetanto@uow.edu.au
}

Follow this and additional works at: https://ro.uow.edu.au/eispapers

Part of the Engineering Commons, and the Science and Technology Studies Commons

Research Online is the open access institutional repository for the University of Wollongong. For further information contact the UOW Library: research-pubs@uow.edu.au 


\title{
Capacity deferral credit evaluation of renewable distributed generation
}

\begin{abstract}
Renewable distributed generation (DG) units can aid in distribution network planning and can be utilized in distribution expansion planning. In order to support the development of distributed renewable resources in the distribution network and to make these resources competitive in the energy market, a well justified credit scheme needs to be devised. In this paper, an analytical method has been developed to estimate the capacity deferral credit of renewable DGs that can be claimed from distribution system operators (DSOs) due to the deferral of conventional distribution network expansion options. The distribution network adequacy has been assessed using the combined multistate availability model of supply sources and load point availability model. A modified load adjustment method has been developed to estimate the effective load carrying capability (ELCC) of renewable DG systems in the distribution network. The renewable DG capacity deferral credit computation procedure is presented and discussed. The proposed technique has been validated using an example radial distribution network and the results show that the proposed method can be used by the DSOs to incentivize the DG owners.
\end{abstract}

\section{Keywords}

distributed, generation, deferral, capacity, credit, evaluation, renewable

Disciplines

Engineering | Science and Technology Studies

\section{Publication Details}

M. A. Abdullah, K. M. Muttaqi, A. P. Agalgaonkar \& D. Sutanto, "Capacity deferral credit evaluation of renewable distributed generation," in Industry Applications Society Annual Meeting, 2013, pp. 1-8. 


\section{Capacity Deferral Credit Evaluation of Renewable Distributed Generation}

\author{
M. A. Abdullah \\ Student Member, IEEE \\ School of Elect., Comp. and \\ Telecom. Engineering \\ University of Wollongong \\ NSW 2522, Australia \\ maa267@uowmail.edu.au
}

\author{
K. M. Muttaqi \\ Senior Member, IEEE \\ School of Elect., Comp. and \\ Telecom. Engineering \\ University of Wollongong \\ NSW 2522, Australia \\ kashem@uow.edu.au
}

\author{
A. P. Agalgaonkar \\ Member, IEEE \\ School of Elect., Comp. and \\ Telecom. Engineering \\ University of Wollongong \\ NSW 2522, Australia \\ ashish@uow.edu.au
}

\author{
D. Sutanto \\ Senior Member, IEEE \\ School of Elect., Comp. and \\ Telecom. Engineering \\ University of Wollongong \\ NSW 2522, Australia \\ soetanto@uow.edu.au
}

\begin{abstract}
Renewable distributed generation (DG) units can aid in distribution network planning and can be utilized in distribution expansion planning. In order to support the development of distributed renewable resources in the distribution network and to make these resources competitive in the energy market, a well justified credit scheme needs to be devised. In this paper, an analytical method has been developed to estimate the capacity deferral credit of renewable DGs that can be claimed from distribution system operators (DSOs) due to the deferral of conventional distribution network expansion options. The distribution network adequacy has been assessed using the combined multistate availability model of supply sources and load point availability model. A modified load adjustment method has been developed to estimate the effective load carrying capability (ELCC) of renewable DG systems in the distribution network. The renewable DG capacity deferral credit computation procedure is presented and discussed. The proposed technique has been validated using an example radial distribution network and the results show that the proposed method can be used by the DSOs to incentivize the DG owners.
\end{abstract}

Index Terms-Capacity deferral credit, distributed generation, distribution network reliability, effective load carrying capability, renewable energy source.

\section{INTRODUCTION}

Electric power industry has encountered considerable changes from the traditional structure, operation and regulation in the last decade and it is expected to adopt further changes within a short period of time [1]. As a consequence of restructuring process, the responsibilities of providing services to the customer have been distributed among the generation, transmission and distribution companies instead of vertically integrated utility structure [2]. The deregulated environment in the electric power industry has enabled the participation of new system operators. Competitive market along with the service standard established by the regulatory authority is driving the economic and reliable operation of the utility. Hence the decentralized energy resources have evolved as competitors for the large generation companies.

Distributed Generation (DG) is one of the most important resources among the decentralized energy resources and is able to play important roles in terms of system operations and market functions in the era of deregulated power industry. The key benefits of DG include improved network operation, economic efficiency, reinforcement deferral and improved reliability of electricity supply [3]. Hence, the importance of DG has been realized by the distribution system operators (DSOs) in distribution network planning.

Due to the governmental incentives, the introduction of advanced technologies and environmental benefits, renewable electricity generation systems are becoming popular to the customers in a distribution network. The increased penetration of renewable DG systems in the distribution network demands adjustment of the conventional operation and planning strategies by the DSO. The assessment of network adequacy and planning tools need to be improved significantly in order to incorporate the peculiarities introduced by the renewable DG systems and development of new tools are required to evaluate additional quantities such as distribution network supply adequacy, capacity deferral credit, probabilistic load flow solutions, return from capital investment etc. for distribution network due to the integration of renewable DG systems.

In view of adopting the changes in electric power industry, as discussed above, this paper proposes an analytical methodology for the supply adequacy assessment of distribution network with renewable DG systems. The distribution network reliability is decomposed into two parts namely: reliability of the supply sources and reliability of the distribution feeder components. Probabilistic models of the distribution network supply source reliability and feeder component reliability have been adopted to estimate the effective load carrying capability (ELCC) of renewable DG systems. The anti-islanding operation of the renewable DG systems and, capacity constraints of the distribution substations and feeder sections are considered in the distribution network reliability estimation models. Time series data of the distribution network load and renewable DG outputs are used in the adequacy evaluation of the distribution network in order to capture the correlation between the quantities due to their diurnal and seasonal variations. A modified load adjustment method has been developed to estimate the ELCC of the renewable DG systems and 
conventional distribution network expansion options. The proposed method is used to estimate the capacity deferral credit that can be attributed to the renewable DG for deferring conventional distribution system expansion and improving reliability of the system. A comparative study highlighting different reliability indices has been presented in this paper to estimate the capacity deferral credit of the renewable DG.

\section{DISTRIBUTION NETWORK EXPANSION PLANNING}

Demand serving capacity, reliability of service and cost of service are three important factors in distribution system planning and operation. Customer load growth results in the existing network capacity to be inadequate in delivering service and the reliability of the network to degrade. The capacity and reliability of the distribution network can be improved by upgrading or adding facilities to the distribution system. However over building the distribution system can result in an expensive facility and higher cost of service. In the competitive market environment, DSOs are bound to provide services to the customers with least cost and hence all possible options to reduce cost of services are to be utilized wisely in distribution network expansion planning.

Customer load growth results in the operation cost of the distribution network to be increased due to the penalty incurred for unreliable services. DSOs are supposed to maintain a minimum level of reliability set by the regulatory organization. Therefore, the DSOs have the obligation to expand the network to increase reliability. The available options for distribution network planner could be adding new feeders, adding new substations or utilizing the DG capacity.

DG systems can be in the form of conventional fuel generators or renewable energy generation systems installed at the utility site or customer site. Greenhouse gas (GHG) emission free electricity generations, cost-effective and efficient technologies, carbon tax legislations and government incentives have expedited the growth of renewable DG systems such as rooftop solar PV, small wind turbine, mini hydro turbine, etc. In the last few years the penetration of renewable DG in the distribution network has increased significantly and it is expected to be continued in the future [4], [5]. It is reasonable to consider the renewable DG systems in distribution network expansion planning by the DSOs. Renewable DGs can support customer load growth in the distribution network and defer the requirement for distribution network expansion.

The renewable DG owners should receive credit for capacity expansion deferral capital cost from the DSOs [6]. In order to assign credit for the renewable DG units, the distribution network planner requires an objective method to assess the capacity support provided by the renewable DG systems to defer the capacity expansion. Due to the variability and unpredictability of renewable sources, renewable generation systems are usually considered as energy resources rather than capacity resources. Capacity resources are those, which can be made available for generation of power to satisfy load demand [5]. Energy resources are the resources which cannot be scheduled. Since traditional planning methods focus on reliability and capacity planning, an increasing penetration of intermittent energy resources imposes challenges to balance the system load demand and the available generation. Hence the capacity contribution evaluation of renewable DGs in the distribution network is a challenging task for the distribution network planners using the traditional planning tools.

The capacity deferral credit evaluation of a renewable DG requires the reliability and adequacy estimation of the distribution network. The reliability of the distribution network depends on the reliability of the equipment, network configuration and the availability of energy supply in the distribution network. Reported methods for adequacy estimation of distribution network with DG can be divided into two major groups: adequacy estimation from the sources of energy supply and adequacy estimation from potential contingencies of the feeder equipment. The supply adequacy estimation methods estimate the risk of adequate supply in the distribution network based on the reliability of substation transformers and the DG systems [7] - [9]. These methods cannot incorporate the risk in serving load due to outage of equipment in the distribution feeder for adequacy estimation. Alternatively, equipment outage based adequacy estimation considers the availability of the feeder sections and lateral equipment in the distribution feeder to estimate the risk of adequate supply to the load points [10]. This method cannot incorporate the risk in energy supply from the distribution substation.

DG systems in the distribution network are usually not allowed to energize the islanded feeder sections as implied by different national and international standards such as IEC 6172 [11], IEEE Standard 929 [12], IEEE Standard 1547 [13] and AS 4777 [14]. This anti-islanding operating condition should also be incorporated in supply adequacy evaluation method.

Since the adequacy due to both inadequate supply from sources and contingency of the distribution feeder are to be considered for adequacy estimation of distribution networks, a new methodology is required for capacity deferral credit of renewable DG system. In this paper an analytical approach is developed to estimate the adequacy of distribution network with renewable DG considering risks from both supply from sources and the availability of equipment in the feeder sections. Hence, the capacity deferral credit of renewable DG can be estimated using the proposed adequacy estimation technique.

\section{CAPACITY DEFERRAL CREDIT OF RENEWABLE DISTRIBUTION GENERATION}

The capacity deferral credit of a renewable DG in distribution network is the percentage of the equivalent capacity of additional distribution facility that can be deferred due to the integration of the DG. The equivalent capacity of 
additional distribution facility can be measured in term of the load growth that the additional facility can support without altering the risk level of the system. The equivalent capacity of a generating unit in the bulk generation system is estimated using several indices such as effective load carrying capability (ELCC), equivalent firm capacity (EFC), capacity factor $(\mathrm{CF})$, etc.

The availability of renewable sources is stochastic in nature. Hence unlike the conventional DG, the installed rated capacity of renewable DG cannot be considered for the firm capacity support. Hence, the equivalent capacity of renewable DG system is used in capacity planning. ELCC is widely used to represent the equivalent capacity of renewable generation unit in capacity planning [15]. The ELCC of a renewable generation unit represents the additional peak load that can be carried by the system after integration of the renewable generation unit without altering the risk level of the system. Hence ELCC indicates the equivalent load growth that can be supported by the integration of renewable DG without any additional expansion facility in the distribution network.

Several indices for loss of load are commonly used for generation system reliability and adequacy assessment in power industry. The loss of load expectation (LOLE) are often used as the system risk level index in estimating the ELCC of a new renewable generation unit in the generation system. The adequacy assessment of distribution network is a relatively new concept and the loss of load indices are not generally used in distribution network reliability assessment. Load point based indices are commonly used for distribution network reliability assessment. In reference [6], the expected energy not served (EENS) is used to compare the reliability improvement caused by the different distribution network expansion options. The reliability index for the ELCC estimation of a new renewable DG is to be selected based on the practice in the DSO to maintain the reliability target of the distribution network. In this paper, LOLE and EENS are separately considered for the ELCC estimation of a renewable DG.

An example distribution system, shown in Fig 1, is considered to illustrate the loading conditions and the required reinforcement from additional facilities and the renewable DG. The load points, which are energized from two distribution substations $\mathrm{U} 1$ and $\mathrm{U} 2$, are connected to the $11 \mathrm{kV}$ radial distribution feeders. There is a tie line with normally opened (N.O.) switch between the feeders emerging out of U1 and U2. The normally closed (N.C.) manual switches are used to ensure continuity of supply between different feeder sections. The peak rating of each substation transformer is 5 MVA. The distribution substation capacities and the length of each feeder section are shown in Fig 1. The peak load and the average load of each load point are shown in Table I. The thermal ratings of the feeder sections are assumed to accommodate the load growth of three times the current peak load. For an outage on either feeder, the healthy feeder cannot supply the entire load of the faulted feeder due to the thermal limitation of the substations. On outages between the load point "C" and substation U1, only the load of load points "D" and "E" can be transferred to the distribution feeder connected to substation U2 after a manual switching action. Similarly on outages between load point "F" and substation $\mathrm{U} 2$, only the load of load points " $\mathrm{G}$ " and " $\mathrm{H}$ " can be transferred to the distribution feeder connected to substation U1 after a manual switching action. Any further load growth in both feeders will result in the transferrable load to be limited to the load points " $E$ " and "H". Hence the reliability of the overall example distribution network degrades and an expansion of the distribution network is required.

The distribution network expansion solutions using an additional substation U3 and a renewable DG are shown in Fig 2 and Fig 3, respectively. The installed rated capacity of both substation U3 and renewable DG is varied in this analysis to model the relative variations between ELCC and the installed rated capacity of both options so that the capacity deferral credit of renewable DG can be evaluated.

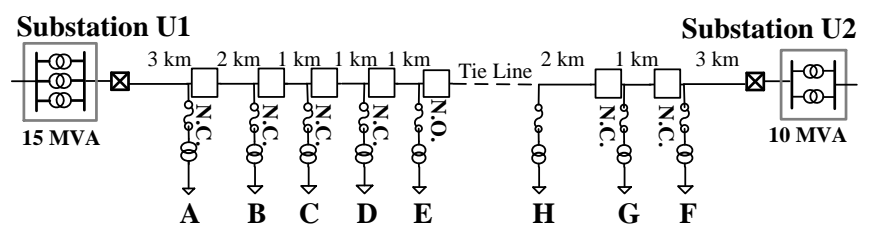

Fig 1: Example radial distribution network configuration.

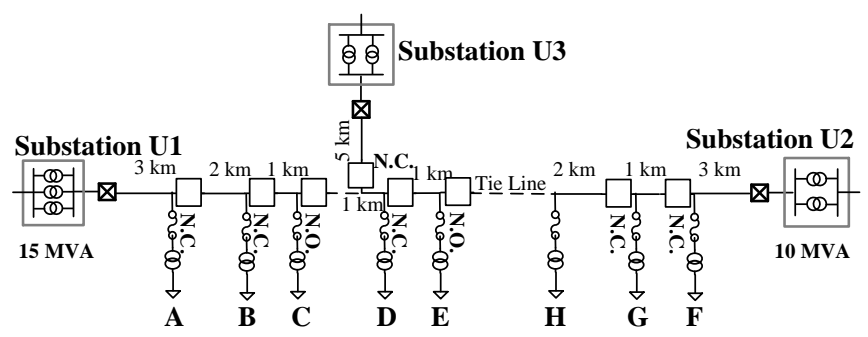

Fig 2: Distribution network expansion option with additional substation U3.

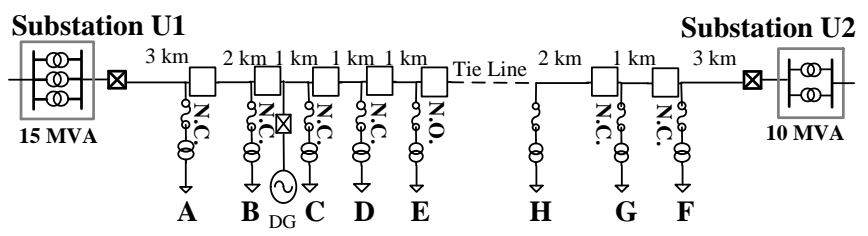

Fig 3: Distribution network expansion option with renewable DG.

\section{CAPACITY DEFERRAL CREDIT EVALUATION OF RENEWABLE DG}

The distribution network services required to satisfy the load can be divided into two groups namely, the energy supply from sources (i.e. distribution substation, DG, tie-line, etc.) and a continuous delivery of the supplied energy to the customer nodes through the network equipment (i.e. feeder, 
protection devices, distribution transformers, etc.). The availability of energy supply from the sources depends on the availability of the upstream generation and transmission facilities, distribution substation transformers and DG capacity. The continuity of energy delivery to the customer ends depends on the availability of the feeder sections, protection devices and distribution transformers. Hence the total reliability of the distribution network is the combinations of the reliability in the energy supply and the reliability of a continuous service delivery. The proposed probabilistic model of the reliability index estimation can incorporate the reliability in the energy supply and the reliability of a continuous service delivery.

TABLE I

PEAK AND AVERAGE LoAD of LOAD POINTS IN Distribution NETWORK

\begin{tabular}{|c|c|c|}
\hline Load Points & Peak Load (MVA) & Average Load (MVA) \\
\hline A & 3.0 & 1.95 \\
\hline B & 3.0 & 1.95 \\
\hline C & 2.0 & 1.30 \\
\hline D & 2.0 & 1.30 \\
\hline E & 1.0 & 0.65 \\
\hline F & 3.0 & 1.95 \\
\hline G & 2.0 & 1.30 \\
\hline H & 2.0 & 1.30 \\
\hline
\end{tabular}

The renewable DG cannot contribute in improving the reliability of continuity in service delivery due to antiislanding operation requirement implied by the standards [11]-[14]. However, renewable DG can contribute to improve the reliability of energy supply from sources. Analytical methods can incorporate the multistate availability model of distribution substation transformers and renewable DG systems. The total reliability estimation of distribution network using analytical method requires probabilistic modeling of the time-varying load, stochastic output of renewable DG, distribution substation, and feeder equipment availability as discussed below.

\section{A. Probabilistic Modeling of Components Availability}

The load demand in distribution network is a time varying quantity and the output of renewable DG is stochastic in nature. Though there exists an uncertainty in both load and renewable DG output, there are some correlation between these two quantities due to their diurnal pattern and seasonal variation. If it is assumed that the load and the renewable DG output variation is independent then it will result in an inaccurate estimation of the distribution network adequacy. In order to consider the correlation between distribution network load and renewable DG output, the coincidental time series data of the quantities are used in this paper. Time series data of at least one full year needs to be considered for the capacity value estimation of renewable DG to incorporate all the seasonal variations and correlations between demand and the renewable DG output.

The distribution substation usually consists of more than one transformer. The outage of one or more transformers will result in decreased capacity to supply the load from the sources. The distribution network substations is modeled by multistate availability model (MSAM) using the forced outage rate (FOR) of the individual transformer [7]. MSAM gives the available capacities $\left(C_{i}\right)$ of distribution network substation along with the probability $\left(P_{i}\right)$ associated with each capacity level. For every time instance, using the MSAM of distribution substations, the output of the renewable DG units $\left(C_{R D G}(t)\right)$ and the FOR of the renewable DG systems $\left(F O R_{R D G}\right)$, the MSAM of the energy supply sources $\left(\operatorname{MSAM}_{S S}(t)\right)$ are generated for reliability estimation of the distribution network as shown in Fig 4.

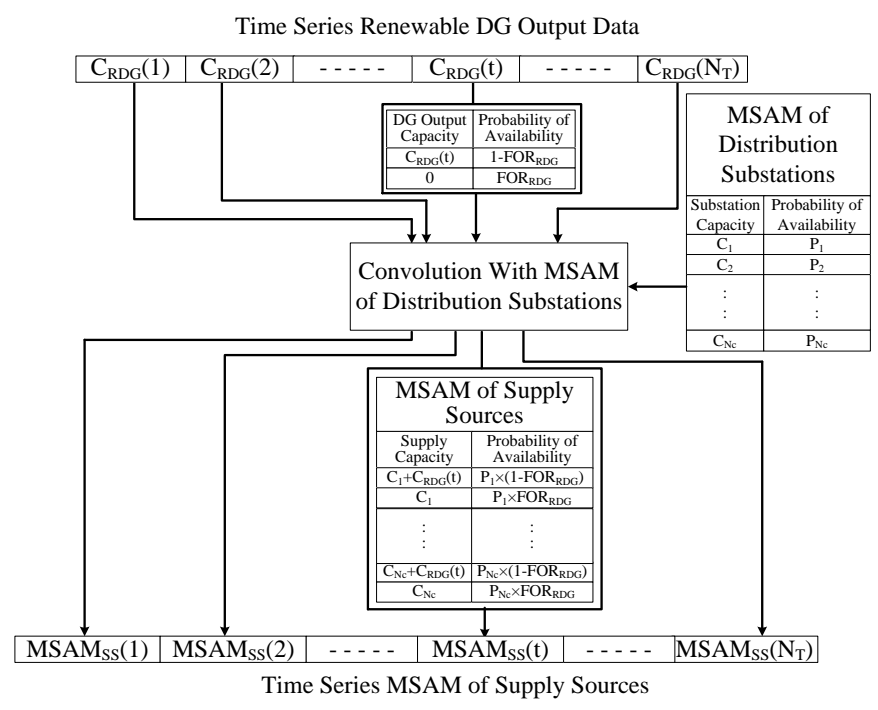

Fig 4: Estimation of time series MSAM of supply sources

The availability of each load point in the distribution network is modeled from the average failure rate $(\lambda)$ and average repair rate $(\mu)$ of the load point [16]. The average failure rate and repair rate of each load point can be estimated using the Zone-Branch method [17]. The probability of the availability and the unavailability of each load point can be estimated using (1) and (2), respectively.

$$
\begin{aligned}
& P\{\text { Availability }\}=\frac{\mu}{\lambda+\mu} \\
& P\{\text { Unavailability }\}=\frac{\lambda}{\lambda+\mu}
\end{aligned}
$$

\section{B. LOLE Estimation}

The loss of load in the distribution network takes place either due to the lack of supply from sources or due to the failure of equipment in the distribution feeders. Hence the loss of load probability (LOLP) in the distribution network for each time instance can be estimated using (3).

$$
L O L P_{D N W}(t)=L O L P_{\text {Source }}(t) \cup L O L P_{\text {Feeder }}(t)
$$

where $L O L P_{D N W}(t)$ is the LOLP in the distribution network during time instance $t, L O L P_{\text {Source }}(t)$ is the LOLP due to lack 
of available supply capacities of the sources during time instance $t$ and is estimated from the load and MSAM of energy sources during that time instance, and $L O L P_{\text {Feeder }}(t)$ is the LOLP in the distribution feeder due to the failure of equipment in the feeder during time instance $t$.

The LOLP of the distribution feeder is the probability that at least one load point is interrupted. The LOLP of a distribution feeder is estimated by accumulating the probability of unavailability for all load points in the distribution feeder. The renewable DG systems cannot improve the LOLP of the distribution feeder due antiislanding operational requirements. However, the renewable DG can contribute in improving the LOLP arising from the lack of energy supply in the distribution network during gridconnected mode of operation. Hence, the impact of renewable DG integration in the distribution network can be observed in the LOLP due to lack of supply capacity. The LOLE of the distribution network is estimated by averaging the LOLP of each time instances within the time period considered in the analysis.

\section{EENS Estimation}

A failure in serving energy to the customers in the load points is the results of the failures of the feeder components connecting the load points to the sources or shortages in the capacities of the sources. Therefore, the EENS in the distribution network can be estimated using equation (4) as follows.

$$
\begin{aligned}
& \operatorname{EENS}_{D N W}= \\
& \sum_{t}\left[\sum_{i}\left(E N S_{S, i, t} \times P_{S, i, t}\right) \cup \sum_{j}\left(E N S_{F, j, t} \times P_{F, j, t}\right)\right] \times P_{t}
\end{aligned}
$$

where $E E N S_{D N W}$ is the total expected energy not served in the distribution network. $E N S_{S, i, t}$ is the energy not served due to the available source capacity level $i$, and $P_{S, i, t}$ is the probability of available capacity level $i$ during time instance $t$. $E N S_{F, j, t}$ is the energy not served due to the outage of load point $j$, and $P_{F, j, t}$ is the outage probability of load point $j$ during time instance $t . \mathrm{P}_{\mathrm{t}}$ is the probability of occurrence at time instance $t$ within the time period of analysis.

The renewable DG systems can only contribute to improve the energy not served and the probability of available source capacity level. The renewable DG cannot improve the energy not served and associated probability due to the outage of load point due to the anti-islanding operation requirement.

\section{Modified Load Adjustment Method}

The estimation of the capacity deferral credit for the renewable DG system in the distribution network requires the ELCC of the renewable DG systems and the ELCC of the conventional distribution network expansion options. A modified load adjustment method is developed to estimate the ELCC of renewable DG systems and conventional distribution network expansion options. The iterative load adjustment method presented in [15] is generally used to estimate the ELCC of a generation unit in the bulk generation system adequacy assessment. In order to include the load transfer operation on the occurrence of an outage in the distribution feeder and the capacity constraints of the distribution substation to accommodate the transferrable load from the neighboring distribution substation feeder, the iterative load adjustment method is modified. The steps in the modified load adjustment method to estimate the ELCC of the renewable DG system and conventional distribution network expansion options are illustrated as follows.

Step 1: Estimate the reliability indices of the distribution network before and after the renewable DG integration (or after implementing the conventional distribution network expansion option).

Step 2: Adjust the load by adding or subtracting a constant $\Delta L$ load to each load point and re-calculate the reliability index of the distribution network with renewable DG (or conventional distribution network expansion option).

Step 3: Modify the restoration and load transfer strategies of the distribution feeders with each $\Delta L$ load addition or subtraction so that the peak load of the reconfigured feeder does not exceed the capacity limits.

Step 4: Continue adjusting the load until the reliability index of distribution network with renewable DG (or conventional expansion option) becomes equal to the reliability index of original distribution network. The difference between the peak of the actual load and the adjusted load is the ELCC of the conventional distribution network expansion option.

\section{E. Capacity Deferral Credit Estimation Methodology}

Comparing the ELCC of the renewable DG systems and the ELCC of the conventional distribution network expansion option, the capacity deferral credit of a renewable DG system can be estimated. The capacity deferral credit of the renewable $\mathrm{DG}$ system, $\mathrm{CDC}_{\mathrm{RDG}}$ is then estimated using Equation (5).

$$
C D C_{R D G}=\frac{\text { ELCCof Renewable DG }}{\text { ELCCof Conventional Expansion Option }}(5)
$$

The steps involved in the ELCC estimation of renewable DG system in the distribution network are illustrated as follows:

Step 1: Select the time period for the analysis and obtain the time series data of the distribution network load demands and the renewable DG output for the selected time period.

Step 2: Estimate the reliability indices of the distribution network before and after the renewable DG integration for each time instance using the time series load data, the MSAM of the distribution substations and the unavailability probability of load points. Compute the expected value of the reliability index from the time series data.

Step 3: Estimate the ELCC of the renewable DG system 
using modified load adjustment method.

Step 4: Obtain the network configuration data for the distribution network with a conventional network expansion option of a certain capacity. Estimate the reliability indices of the distribution network with conventional expansion option for each time instance. Compute the expected value of the reliability index from the time series data.

Step 5: Estimate the ELCC of the conventional network expansion option using modified load adjustment method.

Step 6: Estimate the capacity deferral credit of the renewable DG using the ELCC of the renewable DG system and the ELCC of conventional distribution network expansion option using (5).

The flow diagram of the proposed algorithm for estimating the capacity deferral credit for the renewable DG system in the distribution network is given in Fig 5.

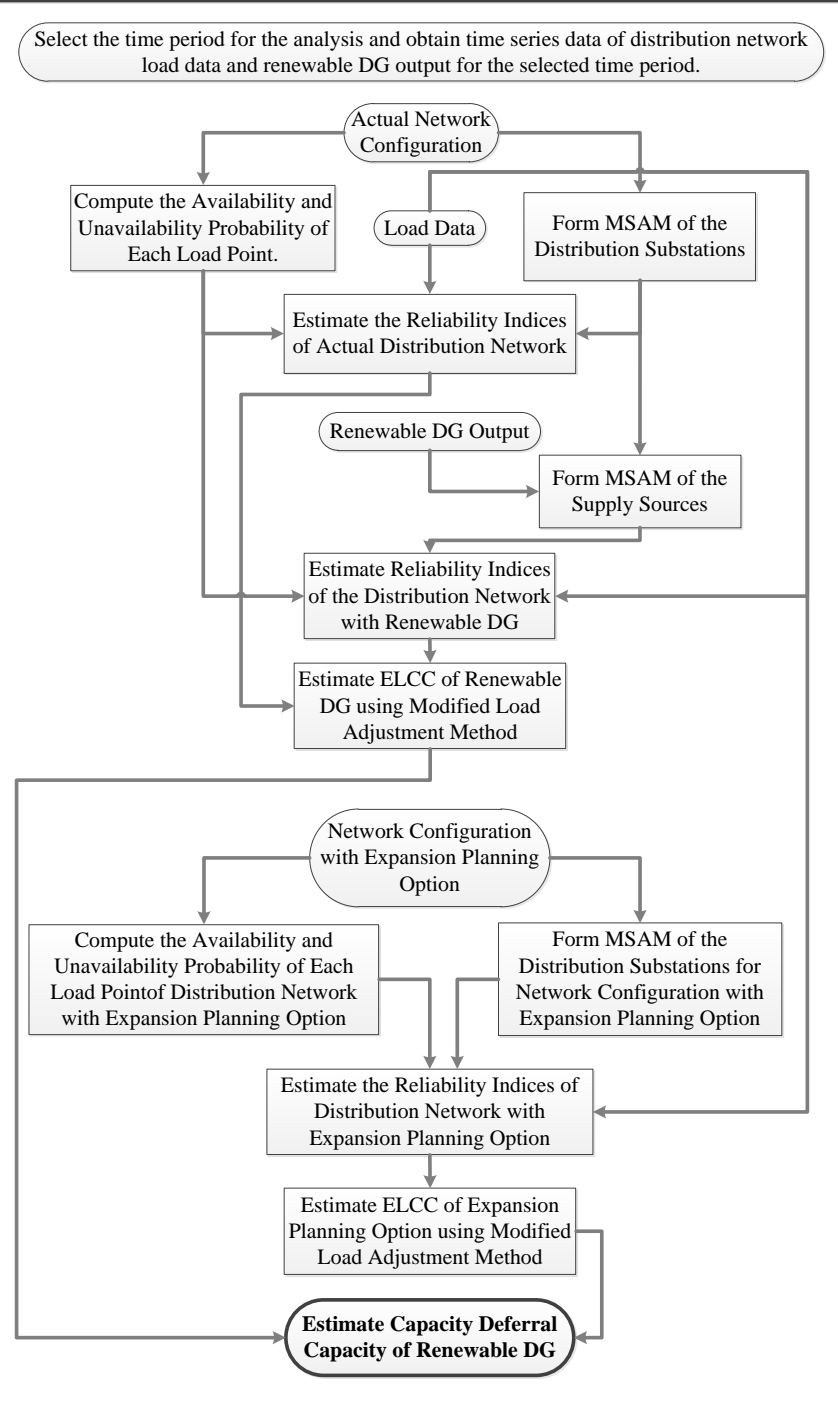

Fig 5: Proposed algorithm for estimating the capacity deferral credit of the renewable DG system.

\section{RESULTS AND DISCUSSIONS}

The capacity deferral credit of a renewable DG in the distribution network shown in Fig 1 is estimated with respect to the conventional distribution expansion planning option shown in Fig 2 using the proposed method. The reliability data of the distribution network components are presented in Table II and Table III. The manual switching time is considered to be 1 hour in this study. The time series data of the distribution network load, wind turbine output and solar PV output are generated using HOMER software [18]. The load factor of the distribution network is 0.66 and the capacity factors of wind turbine DG and solar PV DG are 0.35 and 0.26 , respectively.

TABLE II

RELIABILITY DATA OF DISTRIBUTION NETWORK COMPONENTS

\begin{tabular}{|c|c|c|}
\hline Component & $\begin{array}{c}\text { Failure Rate } \\
\text { (occurrences /year) }\end{array}$ & $\begin{array}{c}\text { Repair Time } \\
\text { (hours) }\end{array}$ \\
\hline Distribution Feeder $(/ \mathrm{km})$ & 0.04 & 2 \\
\hline Manual Switch & 0.01 & 1 \\
\hline Circuit Breaker & 0.002 & 4 \\
\hline Lateral Fuse & 0.1 & 2 \\
\hline Distribution Transformer & 0.01 & 6 \\
\hline
\end{tabular}

TABLE III

RELIABILITY DATA OF ENERGY SUPPLY SOURCES

\begin{tabular}{|c|c|c|}
\hline Component & $\begin{array}{c}\text { Forced Outage Rate } \\
\text { (occurrences/year) }\end{array}$ & $\begin{array}{c}\text { Repair Time } \\
\text { (hours) }\end{array}$ \\
\hline $\begin{array}{c}\text { Distribution Substation } \\
\text { Transformer }\end{array}$ & 0.04 & 24 \\
\hline Renewable DG & 0.01 & 12 \\
\hline
\end{tabular}

In order to observe the impact of the selected reliability indices on the ELCC estimation, the ELCC values of the renewable DG systems and the expansion option with additional substation U3 are estimated using the LOLE and EENS indices. The ELCC values of the wind turbine DG, the solar PV DG and the expansion option with additional substation U3 for different installed rated capacity are shown in Figs. 6, 7 and 9, respectively. It is observed that the ELCC values estimated using LOLE and EENS as reliability indices are mostly analogous to each other. Hence either of the generation system reliability index or distribution network reliability index can be used for ELCC estimation of the resources in distribution network.

It can be noted from Figs. 6 and 7 that the ELCC of the wind turbine DG and the solar PV DG follow the characteristics similar to the ELCC characteristics of renewable generation plants in the bulk generation system. The incremental ELCC of both renewable DG systems decreases as the installed capacity increases. Moreover, it can be noted that the ELCC of the wind turbine DG is higher than the ELCC of the solar PV DG. This is due to the higher capacity factor of the wind turbine DG than the capacity factor of the solar PV DG. On the other hand, the ELCC of the substation U3 increases linearly with the increased capacity of the substation. This is because the higher 
availability rate of distribution substation than the renewable DG systems, and the outage of the distribution substation is independent of the distribution feeder load level.

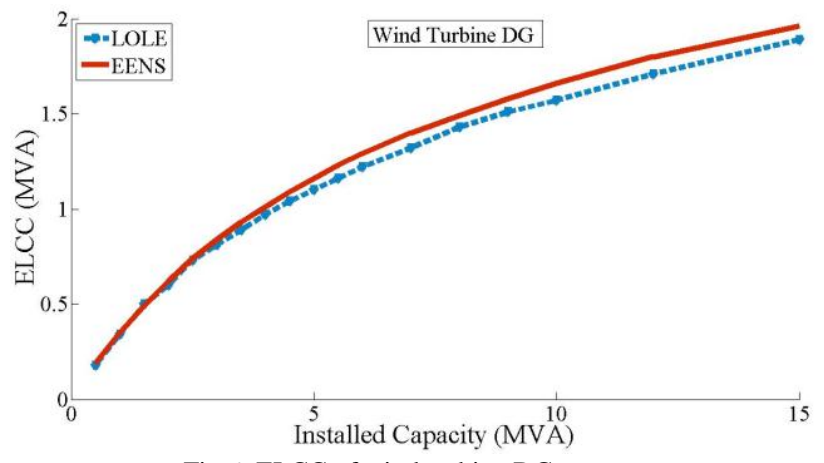

Fig 6: ELCC of wind turbine DG system.

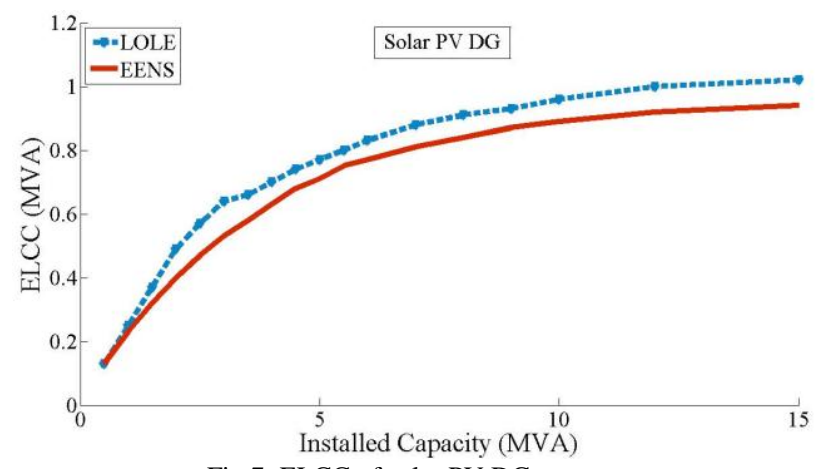

Fig 7: ELCC of solar PV DG system.

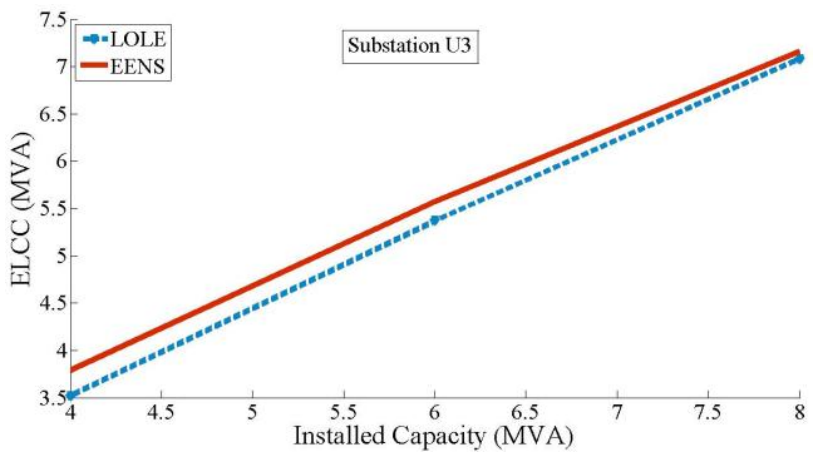

Fig 8: ELCC of conventional expansion option with additional substation $\mathrm{U} 3$

Since the ELCC values of the renewable DG and substation U3 are independent of the selection of reliability index, the ELCC estimated using EENS is utilized to estimate the capacity deferral credit of the wind turbine DG and the solar PV DG systems in the distribution network with respect to different installed capacity value of substation U3. The capacity deferral credits of the wind turbine DG and the solar PV DG systems in the distribution network are estimated using (5) against to the conventional distribution network expansion planning option shown in Fig 2. Conventional distribution network expansion option with three different installed capacities of substation U3 is considered in this study. The variation of capacity deferral credit of wind turbine DG and solar PV DG systems for different installed capacity of the DG systems are shown in Fig 9 and Fig 10, respectively. It is noted from the figures that the capacity deferral credit of the renewable DG systems decreases when the capacity of the substation U3 becomes higher. This indicates that the renewable DG system can receive higher capacity deferral credit from DSO against the short term expansion planning options than the long term expansion planning options of the distribution network. Besides, for this example distribution network with the load and renewable DG output data, the wind turbine DG will receive higher capacity deferral credit than the solar PV DG. This is due to the higher capacity factor and the ELCC value of the wind turbine DG system compared to those from the solar PV DG system.

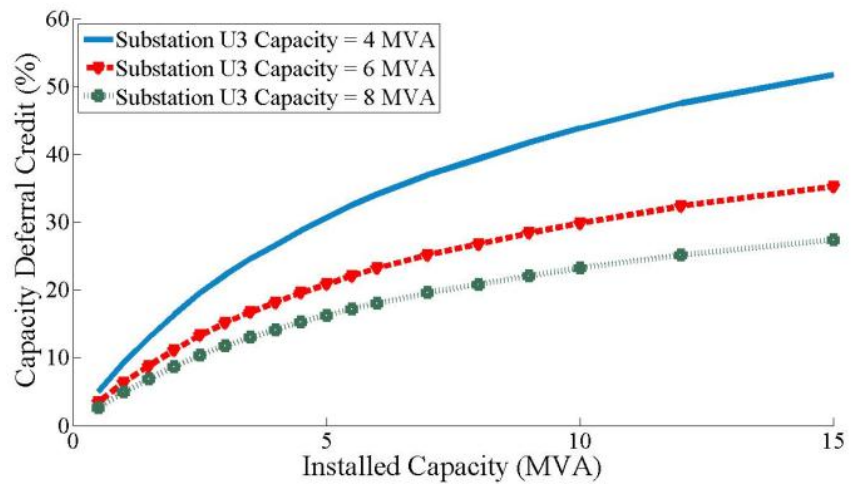

Fig 9: Capacity deferral credit of wind turbine DG system.

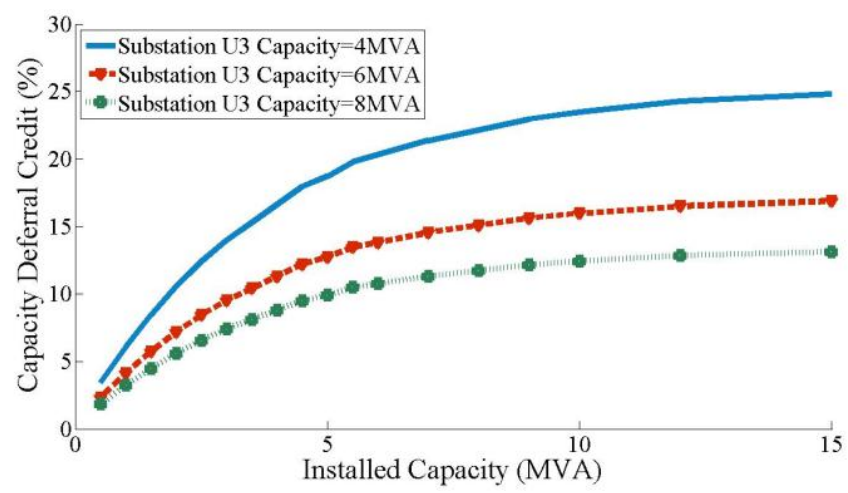

Fig 10: Capacity deferral credit of solar PV DG system.

\section{CONCLUSION}

In this paper, the capacity deferral credit of the renewable distributed generation (DG) has been estimated using an analytical model to quantify the DG benefits against conventional distribution network expansion option. The adequacy of the distribution network is assessed using the combined multistate availability model of sources and the availability of load points in the distribution feeder. The antiislanding requirement implied by the established network standards are taken into consideration in this study. The diurnal and seasonal variation and correlation between distribution network load and available renewable DG output 
have been taken into consideration in the estimation model. A modified load adjustment method has been developed for the distribution network to estimate the ELCC of the renewable DG systems and conventional distribution network expansion options. A systematic procedure has been presented for estimating the capacity deferral credit that a renewable DG owner in the distribution network may receive from the distribution system operators (DSO) due to the deferral of network expansion. The impact of the conventional generation system reliability index and the distribution network reliability index on the effective load carrying capability (ELCC) of the renewable DG systems and conventional distribution network expansion option has been studied. The proposed method for estimating the capacity deferral credit of renewable DG system can be used by the DSO to allocate incentive for the DG owners and hence can contribute in enabling the growth of renewable energy penetration in the decentralized electric power industry.

\section{REFERENCES}

[1] H. B. Puttgen, P. R. MacGregor, F. C. Lambert, "Distributed generation: Semantic hype or the dawn of a new era?," IEEE Power and Energy Magazine, vol. 1, no. 1, pp. 22- 29, Jan-Feb 2003.

[2] J. Driesen, F. Katiraei, "Design for distributed energy resources," IEEE Power and Energy Magazine, vol. 6, no. 3, pp. 30-40, May-June 2008.

[3] H. A. Gil and G. Joos, "On the Quantification of the Network Capacity Deferral Value of Distributed Generation", IEEE Trans. on Power Systems, Vol. 21, No. 4, pp. 1592-1599, 2006.

[4] Australian Energy Market Operator, Rooftop PV information paper, Australia. [Online]. Available: http://www.aemo.com.au/Electricity/ /media/Files/Other/forecasting/R ooftop_PV_Information_Paper.ashx.

[5] U.S. Department of Energy (2008, July), 20\% wind energy by 2030: Increasing wind energy's contribution to U.S. electricity supply, Oak Ridge, TN. [Online]. Available: http://www.nrel.gov/docs/fy08osti/41869.pdf.

[6] A. A. Chowdhury, S. K. Agarwal and D. O. Koval, "Reliability modeling of distributed generation in conventional distribution systems planning and analysis," IEEE Trans. Industry Appl., vol. 39, no. 5, pp. 1493-1498, Sept. 2003.

[7] Y. G. Hegazy, M. M. A. Salama, A. Y. Chikhani, "Adequacy assessment of distributed generation systems using Monte Carlo Simulation," IEEE Trans. Power Systems, vol. 18, no. 1, pp. 48- 52, Feb 2003.

[8] Y. M. Atwa, E. F. El-Saadany, M. M. A. Salama, R. Seethapathy, M. Assam, S. Conti, "Adequacy Evaluation of Distribution System Including Wind/Solar DG During Different Modes of Operation," IEEE Trans. Power Systems, vol. 26, no. 4, pp. 1945-1952, Nov. 2011.

[9] L. D. Arya, L. S. Titare, D. P. Kothari, "Distribution system adequacy assessment accounting customer controlled generator sets," International Journal of Electrical Power \& Energy Systems, vol. 33, no. 5, pp. 1161-1164, June 2011.

[10] G. R. Pudarth, Furong Li, "Locational capacity credit evaluation", IEEE Trans. Power System, vol. 24, pp. 1072-1079, May. 2009.

[11] Photovoltaic (PV) Systems-Characteristics of the Utility Interface, IEC Standard 61727, Dec. 2004.

[12] IEEE Recommended Practice for Utility Interface of Photovoltaic (PV) Systems, IEEE Standard 929-2000, Apr. 2000.

[13] IEEE Standard for Interconnecting Distributed Resources with Electric Power Systems, IEEE Standard 1547, Jul. 2003.

[14] Grid Connection of Energy Systems via Inverters, Australian Standard 4777, Apr. 2005.

[15] A. Keane, M. Milligan, C. J. Dent, B. Hasche, C. D'Annunzio, K. Dragoon, H. Holttinen, N. Samaan, L. Soder, M. O'Malley, "Capacity Value of Wind Power," IEEE Transactions on Power Systems, vol.26, no.2, pp.564-572, May 2011.
[16] R. Billinton and R. N. Allan, "Reliability Evaluation of Power Systems," ( $2^{\text {nd }}$ ed.), Plenum Press, New York, 1996.

[17] W. H. Kersting, W. H. Phillips and R. C. Doyle, "Distribution feeder reliability studies," IEEE Trans. Industry Appl., vol. 35, no. 2, pp. 319323, Mar. 1999.

[18] HOMERenergy, HOMER, [Online], Available: https://analysis.nrel.gov/homer/ 